\title{
Factors controlling hydrochemical and trophic state variables in 86 shallow lakes in Europe
}

Peeter Nõges ${ }^{1,2}$, Tiina Nõges ${ }^{1,2}$, Lea Tuvikene ${ }^{2}$, Halina Smal $^{3}$, Slawomir Ligeza ${ }^{3}$, Ryszard Kornijów $^{4}$, Wojciech Peczula ${ }^{5}$, Eloy Bécares ${ }^{6}$, Francisco Garcia-Criado ${ }^{6}$, Christina AlvarezCarrera $^{6}$, Camino Fernandez-Alaez ${ }^{6}$, Carmen Ferriol ${ }^{7}$, Rosa Maria Miracle ${ }^{7}$, Eduardo Vicente ${ }^{7}$, Susana Romo ${ }^{7}$, Ellen Van Donk ${ }^{8}$, Wouter van de Bund ${ }^{8}$, Jens Peder Jensen ${ }^{9}$, Elisabeth M. Gross $^{10}$, Lars-Anders Hansson ${ }^{11}$, Mikael Gyllström ${ }^{11}$, Mirva Nykänen ${ }^{12}$, Elvira de Eyto ${ }^{13}$, Kenneth Irvine ${ }^{13}$, Deborah Stephen ${ }^{14}$, Sally Collings ${ }^{14} \&$ Brian Moss ${ }^{14}$

${ }^{1}$ Institute of Zoology and Hydrobiology, University of Tartu, Vanemuise 46, 51014 Tartu, Estonia

E-mail:pnoges@zbi.ee

${ }^{2}$ Võrtsjärv Limnological Station, Institute of Zoology and Botany, Estonian Agricultural University, 61101 Rannu,

Tartu county, Estonia

${ }^{3}$ Institute of Soil Science and Environment Management, Agricultural University, Leszczyñskiego 7, 20-067 Lublin,

Poland

${ }^{4}$ Department of Hydrobiology and Ichthyobiology, Agricultural University, Akademicka 13, 20-950 Lublin, Poland

${ }^{5}$ Department of Botany and Hydrobiology, Catholic University of Lublin, Norwida 4, 20-061 Lublin, Poland

${ }^{6}$ Department of Ecology, Faculty of Biology, University of Leon, 24071 Leon, Spain

${ }^{7}$ Department of Microbiology \& Ecology, University of Valencia, Dr. Moliner 50, 46100 Burjassot (Valencia), Spain

${ }^{8}$ NIOO-Centre for Limnology, Rijksstraatweg 6, 3631 AC Nieuwersluis, The Netherlands

${ }^{9}$ Natural Environment Research Institute, Vejlsøvej 25, 8600 Silkeborg, Denmark

${ }^{10}$ Limnological Institute, Department of Biology, University of Konstanz, P.O. Box M659, D-78457 Konstanz, Germany

${ }^{11}$ Institute of Ecology and Limnology, Ecology building, SE-223 62 Lund, Sweden

${ }^{12}$ Department of Ecology and Environmental Sciences, Niemikatu 73, 15140 Lahti, Finland

${ }^{13}$ Department of Zoology, College Green, Trinity College Dublin, Dublin 2, Ireland

${ }^{14}$ School of Biological Sciences, Derby Building, University of Liverpool, L69 3GS Liverpool, U.K.

Key words: ecological status, European shallow lakes, hydrochemistry, latitude

\begin{abstract}
In order to disentangle the causes of variations in water chemistry among European shallow lakes, we performed standardised sampling programs in 86 lakes along a latitudinal gradient from southern Spain to northern Sweden. Lakes with an area of 0.1 to 27000 ha and mean depth of 0.4-5.6 m located in low to high altitudes were investigated within the EC project ECOFRAME 1-4 times during June-October 2000-2001. Several variables like conductivity, alkalinity, abundance of submerged plants, concentrations of suspended solids, total nitrogen and phosphorus were latitude-dependent decreasing from south to north. Secchi depth, concentrations of total nitrogen, total phosphorus, suspended solids, and chlorophyll $a$ correlated strongly with the presumed quality classes of the lakes. We came to the conclusion that the variability of shallow lakes in Europe is still mostly dependent on natural differences. Variables connected to lake morphometry, seasonality, basin geology and climate explained altogether nearly half of the total variability of lakes. The trophic state factor, describing mostly the human influence on lakes, was the strongest single factor responsible for nearly a quarter of the total variability of the studied European lakes.
\end{abstract}




\section{Introduction}

Investigations based on a large number of lakes usually cover small geographic ranges. This kind of regional study is known from many parts of the World like Denmark (Jensen et al., 1990), Norway (Faafeng \& Hessen, 1993), Estonia (Ott et al., 1999), and Florida (Duarte et al., 1992), United Kongdom (Maberly et al., 2003), and Germany (Mathes et al., 2003). Wider geographical overviews (Schindler, 1978; Kalff, 1991; Cobelas \& Rojo, 1994) are generally based on data collected from the literature, inevitably leading to inclusion of variability caused by methodological differences. In order to improve our understanding of the considerable large scale variations in lake water chemistry, we performed standardised sampling programs throughout Europe.

In the present paper, we summarise the results of statistical analyses of general limnological data performed according to a unified methodology on a set of 86 shallow lakes ranging in latitude from southern Spain to northern Sweden. The aim of our study was to find out which part of the total variability in water chemistry among European shallow lakes could be explained by natural, i.e. climatic and morphoedaphic differences, and which part could be attributed to anthropogenic influences.

\section{Description of the lakes studied}

Eighty-six shallow lakes in Europe were chosen to cover most of the European latitudinal and longitudinal ranges and the major part of the variability in terms of lake size, basin geology, and nutrient status. Eighteen lakes were from Spain and six to ten lakes from each of the other countries including Denmark, Estonia, Finland, Germany, Great Britain, Ireland, The Netherlands, Poland, and Sweden. Lakes with an area from 0.1 to 27000 ha (median $27 \mathrm{ha}$ ) and mean depth from 0.4 to $5.6 \mathrm{~m}$ (median $1.6 \mathrm{~m}$ ) distributed within a latitude range from $39^{\circ}$ to $68.5^{\circ} \mathrm{N}$ (Table 1 ) and in low to high altitudes. Polymixis was the main criterion to distinguish between shallow and deeper lakes (Padisák $\&$ Reynolds, 2003). The lakes differed in their thermal regimes from non-freezing to lakes with a more than 4 months ice-cover. The conductivity of lake water ranged from 5 to $18900 \mu \mathrm{S} \mathrm{cm}^{-1}$, but according to the median value $\left(306 \mu \mathrm{S} \mathrm{cm}{ }^{-1}\right)$ most of the water bodies were freshwater lakes. The basins were either calcareous, silicious, peaty or a combination of these types.

\section{Materials and methods}

In the year 2000, 66 shallow lakes of different ecological quality were sampled 2-3 times during JuneOctober by each of the 11 partners ( 6 by each partner) connected to the European Union project ECOFRAME. A general limnological characterisation of the lakes was made in terms of altitude and latitude of the location, morphometric features (area, mean and maximum depth), basin geology, and ice conditions. In order to characterise vegetation abundance, the percentage of the lake volume 'infested' by submerged macrophytes (PVI) (Canfield et al., 1984) was calculated. A similar set of physical and chemical variables including water transparency as Secchi depth, conductivity, $\mathrm{pH}$, total alkalinity, light absorbance at 400 $\mathrm{nm}$, and the concentrations of total phosphorus, total nitrogen, and chlorophyll $a$ was measured by each partner. In the year 2001, 20 new lakes were chosen to displace some of the earlier ones. The new set of lakes was sampled only once according to a simplified sampling program from which measurements of total alkalinity, light absorption, and suspended solids concentration were omitted.

Water samples were taken as integrated tube or sampler samples from the central part of the lake. Water transparency (SD) was measured with Secchi disc. Conductivity (COND) and $\mathrm{pH}(\mathrm{PH})$ were measured in unfiltered water using electronic $\mathrm{pH}$ and conductivity meters. We used methyl orange to determine the end point in total alkalinity titration with $0.05 \mathrm{~N} \mathrm{HCl}$. Chlorophyll $a$ (CHL) was extracted from filters with 96\% ethanol and concentration calculated according to Arvola (1981). Suspended solids (SS) were determined on preweighed Whatman GF/C filters after drying at $105^{\circ} \mathrm{C}$ for $2 \mathrm{~h}$. As a measure of humic substances concentration, spectrophotometric light absorption at $400 \mathrm{~nm}$ (A400) was measured in filtered (Whatman $\mathrm{GF} / \mathrm{C}$ ) water against distilled water using $5-\mathrm{cm} \mathrm{cu}-$ vettes. Total phosphorus (TP) was measured by the molybdenum blue reaction according to Murphy \& Riley (1962) after potassium persulfate digestion. For total nitrogen (TN) mostly the Kjeldahl method was used, however partners were free to use their own methods.

Codings were used for some variables to make them numeric. To describe basin geology (GEOL), code 1 was used for predominantly mineral soils, both calcareous and siliceous, and code 2 for organic (peaty) basins. In cases where both types of soils were almost equally represented, the code 1.5 was used. 
Table 1. Descriptive statistics of the main variables characterising the set of 86 shallow European lakes

\begin{tabular}{|c|c|c|c|c|c|c|c|}
\hline Variable, unit & Abbreviation & Valid N & Mean & Median & Min. & Max. & Std.Dev. \\
\hline Month, number & MONTH & 203 & 7 & 7 & 6 & 10 & 1 \\
\hline Secchi depth, m & $\mathrm{SD}$ & 203 & 1.5 & 1.1 & 0.2 & 6.9 & 1.3 \\
\hline Conductivity, $\mu \mathrm{S} \mathrm{cm}^{-1}$ & COND & 203 & 978 & 306 & 5 & 18900 & 2767 \\
\hline North latitude, degrees & LAT & 203 & 52.3 & 52.4 & 39.0 & 68.5 & 7.2 \\
\hline Mean depth, m & ZAV & 203 & 1.8 & 1.6 & 0.4 & 5.6 & 0.9 \\
\hline Maximum depth, m & ZMAX & 189 & 3.9 & 2.7 & 1.0 & 16.0 & 2.6 \\
\hline Area, ha & AREA & 203 & 669 & 27 & 0.1 & 27000 & 3329 \\
\hline \multicolumn{8}{|l|}{ Percentage volume infested } \\
\hline (PVI) by submerged plants, $\%$ & & 186 & 19 & 7 & 0 & 100 & 26 \\
\hline Suspended solids, $\mathrm{mg} \mathrm{l}^{-1}$ & SS & 155 & 14.1 & 7.3 & 0.2 & 127.2 & 20.1 \\
\hline Light absorption at $400 \mathrm{~nm}, 5 \mathrm{~cm}^{-1}$ & A400 & 149 & 0.11 & 0.09 & 0.01 & 0.85 & 0.11 \\
\hline $\mathrm{pH}$ & PH & 203 & $6.38^{a}$ & 8.11 & 4.28 & 9.93 & 0.96 \\
\hline Alkalinity, meq $1^{-1}$ & ALK & 137 & 2.12 & 1.68 & 0.03 & 6.61 & 1.60 \\
\hline Total phosphorus, $\mathrm{mg} \mathrm{m}^{-3}$ & $\mathrm{TP}$ & 203 & 98 & 53 & 2 & 753 & 120 \\
\hline Total nitrogen, $\mathrm{mg} \mathrm{m}^{-3}$ & $\mathrm{TN}$ & 203 & 1916 & 1206 & 227 & 12938 & 2029 \\
\hline Chlorophyll $a, \mathrm{mg} \mathrm{m}^{-3}$ & CHL & 198 & 40.6 & 16.4 & 0.3 & 426.9 & 64.0 \\
\hline
\end{tabular}

${ }^{a}$ Negative logarithm of the average $\left[\mathrm{H}^{+}\right]$concentration.

All investigators were asked to give an expert opinion of the ecological quality of the lakes. This status (STATUS) of lakes was evaluated in a scale of five categories recommended by the EU Water Framework Directive (EC Directive, 2000) with code 1 corresponding to bad, 2 to poor, 3 to moderate, 4 to good, and 5 to high status. To describe the length of the icecover (ICE), code 0 was used for non-freezing lakes, code 1 for lakes frozen for less than 2 months, and code 2 for lakes where the ice-cover lasts more than 2 months. The altitude (ALT) was marked by 1 for lowland lakes, by 2 for middle-altitude lakes, and by 3 for high-altitude lakes.

Statistical analysis of data was performed using STATISTICA for Windows 5.0 (StatSoft, Inc., 1995). For cluster analysis, nine variables measured in all 86 lakes (SD, COND, LAT, ZAV, ICE, PH, TP, TN, CHL) were standardised by subtracting the mean of each variable and dividing the residuals by the standard deviation. Using the $k$-means clustering procedure, the lakes were grouped into five clusters. We used Principal components as the extraction method for factor analysis and 'Varimax normalised' as the rotation type. Eigenvalue $>1$ was used as the criterion for the appropriate number of factors. Missing values were deleted pairwise.
Table 2. Numbers of lakes in clusters separated on the basis of nine variables (SD, COND, LAT, Zav, ICE, PH, TP, TN, $\mathrm{CHL}$ ) using the $k$-means clustering procedure

\begin{tabular}{|c|c|c|c|c|c|c|}
\hline \multirow[t]{2}{*}{ Country } & \multicolumn{6}{|c|}{ Cluster } \\
\hline & 1 & 2 & 3 & 4 & 5 & Total \\
\hline Sweden & & & 1 & 1 & 5 & 7 \\
\hline Finland & & & & 1 & 5 & 6 \\
\hline Estonia & & & & 6 & 3 & 9 \\
\hline Denmark & & & & 5 & 1 & 6 \\
\hline Germany & & & 6 & 2 & 1 & 9 \\
\hline United Kingdom & 1 & 3 & 6 & & & 10 \\
\hline Ireland & & & 8 & & 1 & 9 \\
\hline Poland & & 1 & & 5 & & 6 \\
\hline The Netherlands & & 1 & 5 & & & 6 \\
\hline Spain (Leon region) & & 2 & 9 & & 1 & 12 \\
\hline Spain (Valencia region) & 3 & 1 & 2 & & & 6 \\
\hline Total: & 4 & 8 & 37 & 20 & 17 & 86 \\
\hline
\end{tabular}

\section{Results}

\section{Cluster analysis}

Three variables (TP, TN, ICE) of the nine used for grouping the lakes had a significantly smaller withincluster variability compared with the between-cluster variability when the lakes were divided into five 


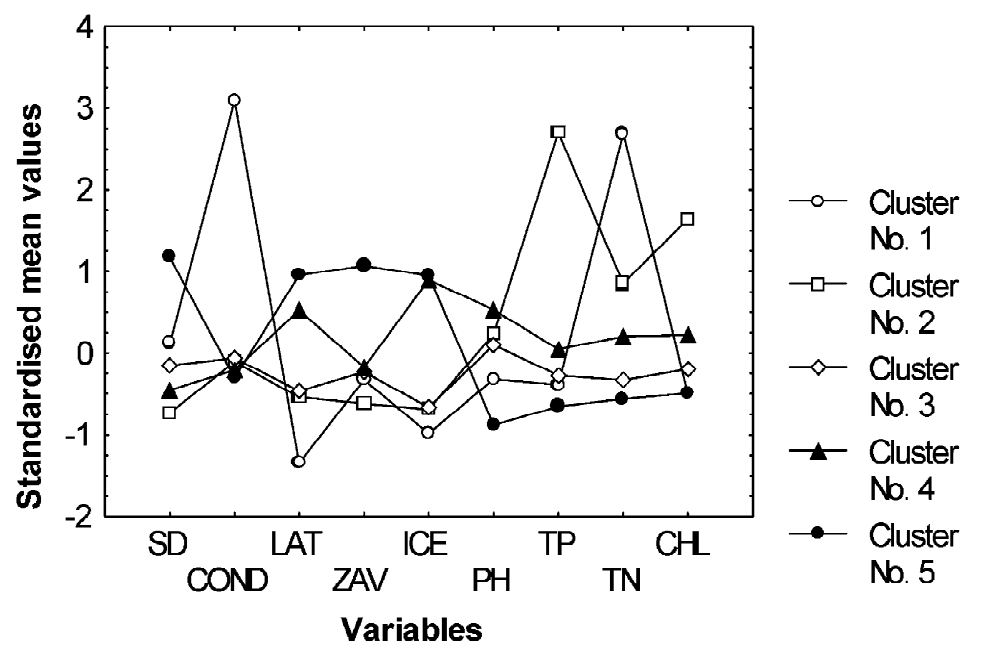

Figure 1. Standardised mean values of variables in clusters of lakes.

clusters. According to the standardised mean values of the variables (Fig. 1) the first cluster could be described as consisting of southern lakes with increased salinity and nitrogen concentration but with relatively low phosphorus and chlorophyll concentrations. This cluster contained four lakes (Table 2): three from Valencia region and one from the U.K. because of its extreme nitrogen concentration (Little Budworth Mere, $11.5 \mathrm{mg} \mathrm{N}^{-1}$ ). Cluster 2 joined generally turbid lakes with high TP and high CHL with missing or short ice-cover. Cluster 3 was the largest containing 37 lakes. It was the medium group in almost every respect. Cluster 4 consisted mainly of shallow northern lakes, with low water transparency in spite of low chlorophyll concentrations. The lakes in cluster 5 were generally deeper and characterised by low trophic state and high transparency.

\section{Relationships between the variables}

All well-known water quality parameters like Secchi depth, concentrations of suspended solids, total nitrogen, total phosphorus and chlorophyll were exponentially related with the presumed quality classes of the lakes (Fig. 2). Differences between the median values of the variables in neighbouring quality classes were mostly statistically significant except between 'poor' and 'bad', because only three lakes were considered 'bad'. High quality lakes were significantly deeper than the lakes qualified as 'moderate', 'poor' or 'bad'. Several variables correlated significantly $(p<$ $0.01)$ with geographic latitude. There was a northward increase in ICE $(r=0.59)$, ln AREA $(r=0.49)$, and $\ln \mathrm{ZAV}(r=0.31)$, and a decrease in $\ln$ COND $(r=-0.58), \ln \mathrm{TN}(r=-0.49), \ln \operatorname{ALK}(r=$ $-0.44)$, In PVI $(r=-0.38)$, PH $(r=-0.31)$, ln SS $(r=-0.26), \ln \mathrm{SD}(r=0.22)$, and $\ln \mathrm{TP}$ $(r=-0.22)$. Neither CHL nor A400 correlated with latitude.

There were groups of interrelated variables (Fig. 3 ) that could be defined as variables connected with lake basin geology (PH, ALK, COND), with trophic status (LAT, ALK, TP, TN, CHL) and with water optics (ZAV, SD, SS, A400, CHL). Slightly saline lakes under marine influence caused a loss of linearity in the alkalinity-conductivity relationship.

\section{Factor analysis}

Seven factors explaining more than $70 \%$ of the total variance were extracted from 19 variables included in the analysis (Table 3 ).

\section{Discussion}

The high number of latitude-sensitive variables and the strength of correlations demonstrates the sensitivity of mostly physically driven shallow lakes to geological and climatic forcing. Similarly to Kalff (1991) who studied the effect of latitude on nutrients, biomass and production in lakes worldwide, we found a southward increase in TP and no trend in CHL.

Four variables commonly used to characterise the trophic status of lakes (SD, SS, TP, CHL) had the highest loadings (abs. value $>0.5$ ) to $\mathrm{F} 1$ in the factor 

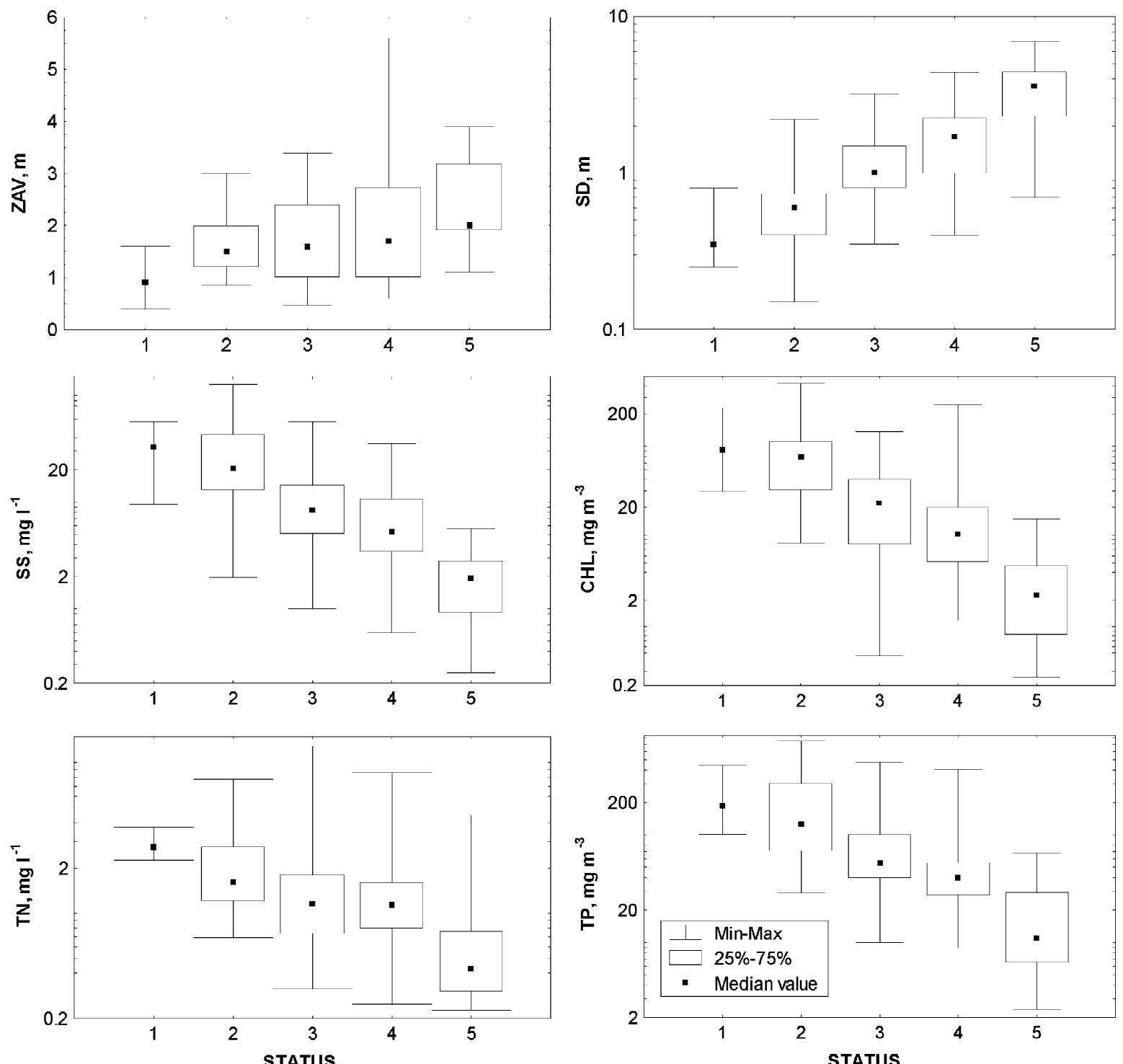

Figure 2. Variability of lake mean depth and of variables commonly used as water quality indicators within presumed water quality classes for lakes investigated. Water quality in lakes was estimated as expert opinion from 'bad'=1 to 'high'=5.

analysis. In spite of the wide range of climatic regions and lake types involved, this 'trophic state factor' explained the largest part of the variability in the database. A certain fraction of the differences in trophic status can be attributed directly to natural differences in soil fertility regarding, e.g. the morphoedaphic index by Vighi \& Chiaudani (1985). Even more, the exceptionally high phosphorus concentrations in some meres of North West England included in the analysis may be of natural origin dependent on the local geochemistry (Moss et al., 1997). However, in most cases anthropogenic eutrophication is responsible for high nutrient concentrations in lakes and has become the leading force in structuring lake ecosystems in Europe. As naturally more fertile soils are preferably used for agriculture, anthropogenic eutrophication emphasises the natural differences. LAT and variables correlated with latitude (PVI, COND and TN) had largest factor weights in F2. F3 was the depth factor. Deeper lakes were generally less humic and had a higher transparency. F4 was mostly influenced by altitude, ice conditions and basin geology and so it characterised, 
Variables connected with lake basin geology
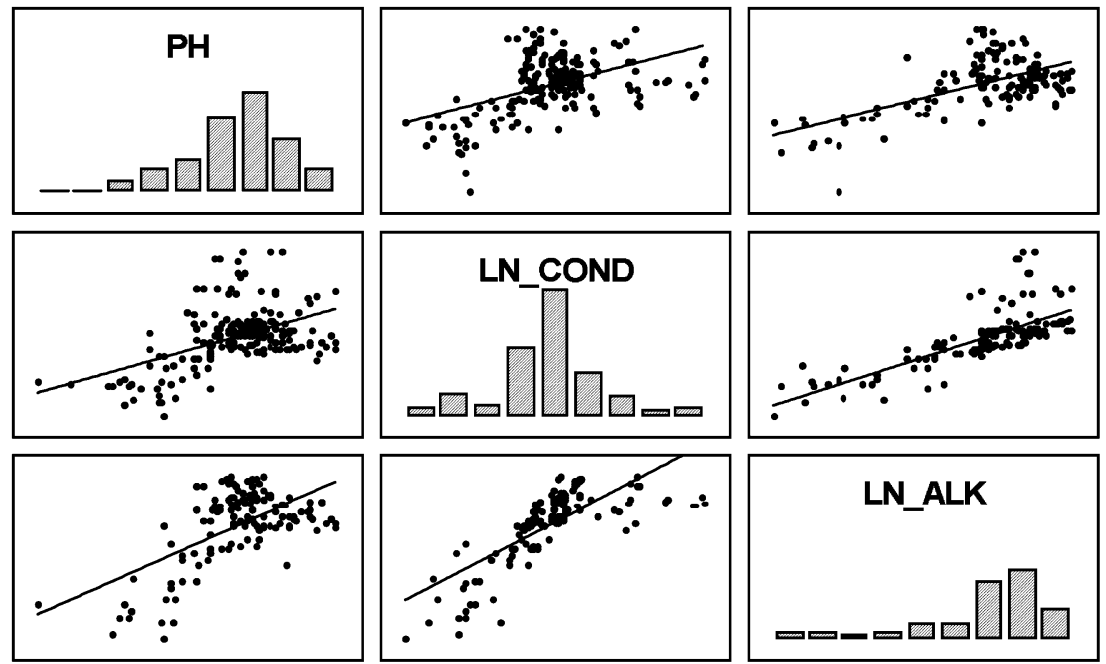

Variables connected with trophic status

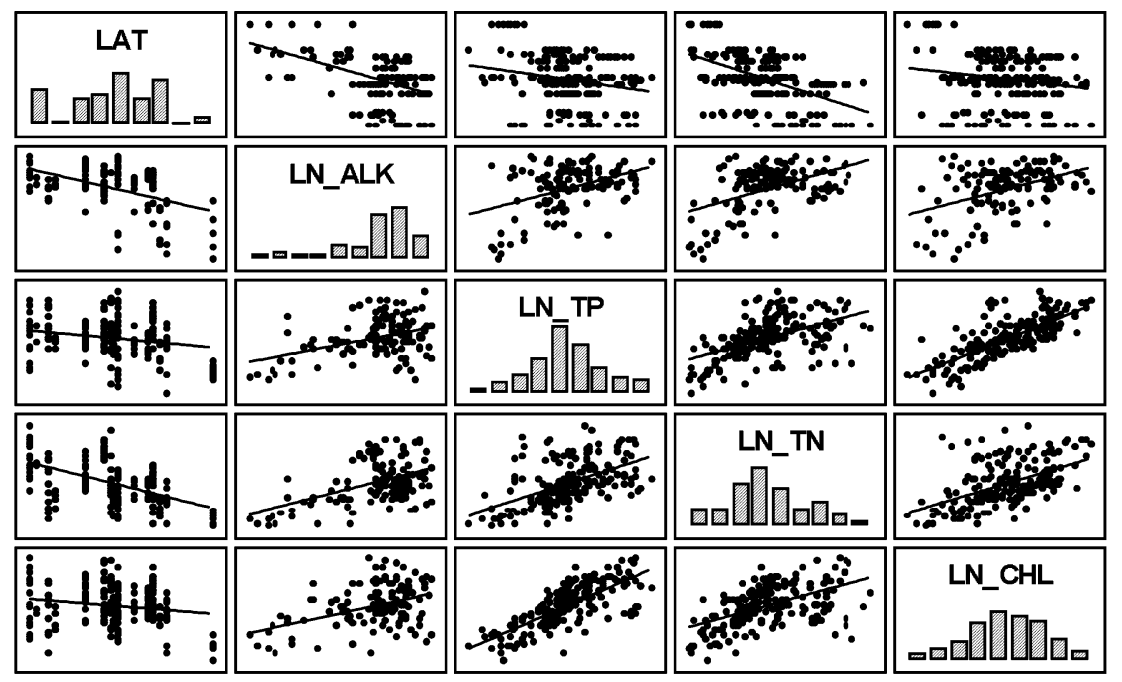

Figure 3. Regression matrices of intercorrelated variables. Distribution histograms of the variables are shown in the diagonal fields. Natural logarithm was used to normalise the distribution of most of the variables.

in some respect, also the maritime-continental transition. Factors 5-7 were strongly influenced by one variable each: F5 by sampling month, F6 by lake area, and F7 by sampling year.

Based on the analyses we came to the conclusion that the variability of shallow lakes in Europe is still mostly dependent on natural differences. Variables connected to lake morphometry, seasonality, basin geology and climate explained altogether nearly half of the total variability of lakes. The trophic state factor describing mostly the human influence on lakes has become the strongest single factor responsible for nearly a quarter of the total variability of European lakes.

\section{Acknowledgements}

Funding for this research was provided by the European Union project ECOFRAME (contract EVK1-CT-1999-39), and by Estonian Science Foundation grant 4080 . 
Variables connected with water optics

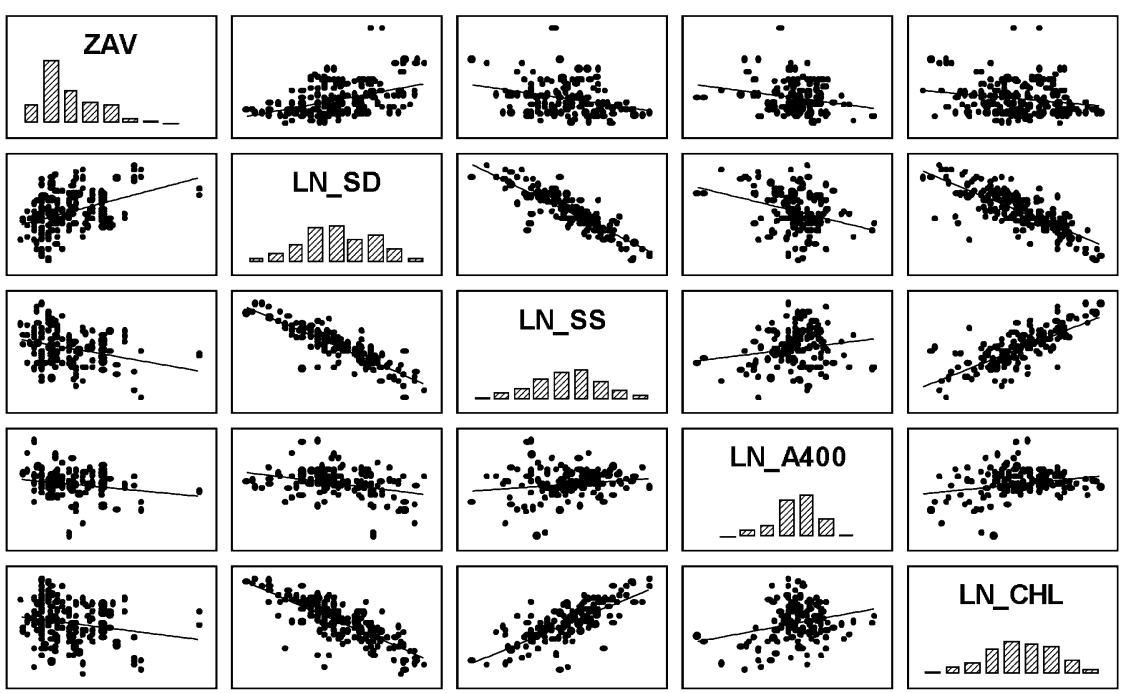

Figure 3. (Continued.)

Table 3. Factor weights of 19 variables used in the analysis. Weights with an absolute value $>0.7$ are marked in bold

\begin{tabular}{|c|c|c|c|c|c|c|c|}
\hline \multirow[t]{2}{*}{ Variable } & \multicolumn{7}{|c|}{ Factor } \\
\hline & F 1 & F 2 & F 3 & F 4 & F 5 & F 6 & F 7 \\
\hline MONTH & 0.01 & -0.02 & 0.08 & 0.03 & 0.84 & 0.00 & -0.26 \\
\hline YEAR & -0.02 & 0.06 & 0.01 & 0.01 & -0.23 & 0.05 & 0.82 \\
\hline SD & 0.51 & -0.01 & 0.58 & 0.13 & 0.00 & -0.23 & -0.03 \\
\hline COND & 0.02 & 0.65 & -0.02 & 0.11 & -0.09 & -0.08 & 0.07 \\
\hline LAT & 0.16 & -0.81 & 0.17 & 0.26 & -0.05 & -0.08 & 0.04 \\
\hline ALT & -0.16 & 0.30 & -0.11 & 0.81 & -0.03 & 0.16 & 0.02 \\
\hline ZAV & 0.17 & -0.21 & 0.79 & -0.01 & 0.14 & 0.04 & 0.07 \\
\hline ZMAX & 0.18 & -0.23 & 0.83 & -0.06 & 0.10 & -0.03 & 0.10 \\
\hline AREA & 0.06 & -0.19 & 0.01 & 0.16 & 0.02 & 0.79 & 0.10 \\
\hline GEOL & -0.02 & -0.19 & -0.14 & 0.53 & -0.37 & -0.40 & -0.27 \\
\hline PVI & 0.36 & 0.67 & -0.33 & 0.01 & 0.04 & 0.03 & -0.13 \\
\hline ICE & 0.13 & -0.43 & 0.22 & 0.69 & 0.27 & 0.07 & 0.07 \\
\hline SS & -0.89 & 0.11 & -0.12 & 0.07 & 0.12 & 0.03 & 0.02 \\
\hline A400 & 0.11 & -0.25 & -0.62 & 0.06 & 0.35 & -0.20 & 0.30 \\
\hline $\mathrm{PH}$ & -0.33 & 0.31 & -0.14 & 0.03 & -0.18 & 0.53 & -0.37 \\
\hline ALK & -0.11 & 0.43 & 0.08 & -0.34 & 0.06 & 0.44 & -0.06 \\
\hline $\mathrm{TP}$ & -0.72 & -0.05 & -0.18 & -0.13 & -0.14 & -0.06 & -0.05 \\
\hline $\mathrm{TN}$ & -0.49 & 0.61 & -0.02 & 0.35 & 0.02 & -0.05 & 0.20 \\
\hline $\mathrm{CHL}$ & -0.88 & 0.01 & -0.05 & 0.11 & -0.03 & 0.07 & -0.02 \\
\hline Eigenvalue & 4.25 & 2.34 & 1.86 & 1.65 & 1.31 & 1.15 & 1.01 \\
\hline Explained variance & 22 & 12 & 10 & 9 & 7 & 6 & 5 \\
\hline Cumulative explained variance & 22 & 35 & 44 & 53 & 60 & 66 & 71 \\
\hline
\end{tabular}




\section{References}

Arvola, L., 1981. Spectrophotometric determination of chlorophyll $a$ and phaeopigments in ethanol extractions. Annales Botanici Fennici 18: 221-227.

Canfield, D. E. J., J. V. Shireman, D. E. Colle \& W. T. Haller 1984. Prediction of chlorophyll $a$ concentrations in Florida lakes: importance of aquatic macrophytes. Can. J. Fish. aquat. Sci. 41: 497-501.

Cobelas, M. A. \& C. Rojo, 1994. Spatial, seasonal and long-term variability of phytoplankton photosynthesis in lakes. J. Plankton Res. 16: 1691-1716.

Duarte, C., S. Agusti \& D. E. Jr. Canfield, 1992. Patterns in phytoplankton community structure in Florida lakes. Limnol. Oceanogr. 37: 155-161.

EC Directive 2000/60/EC. Directive of the European Parliament and of the Council of the European Union establishing a framework for community action in the field of water policy. Council of the European Union, Brussels: $66 \mathrm{pp}$.

Faafeng, B. A. \& D. O. Hessen, 1993. Nitrogen and phosphorus concentrations and N:P ratios in Norwegian lakes: Perspectives of nutrient limitation. Verh. int. Ver. theor. angewan. Limnol. 25: 465-469.

Jensen, J. P., P. Kristensen \& E. Jeppesen, 1990. Relationships between nitrogen loading and in-lake nitrogen concentrations in shallow Danish lakes. Verh. int. Ver. theor. angewan. Limnol. 24: 201-204.

Kalff, J., 1991. The utility of latitude and other environmental factors as predictors of nutrients, biomass and production in lakes worldwide: problems and alternatives. Verh. int. Ver. theor. angewan. Limnol. 24: 1235-1239.

Maberly, S. C., L. Kling, C. E. Gibson, L. May, R. I. Jones, M. M. Dent \& C. Jordan, 2003. Linking nutrient limitation and water chemistry to catchment characteristics. Hydrobiologia 506-509: 83-91.

Mathes, J. I. Korczynski \& J. Müller, 2003. Shallow lakes in Northeast Germany - Trophic situation and restoration programmes. Hydrobiologia 506-509: 797-802.

Moss, B., M. Beklioglu, L. Carvalho, S. Kilinc, S. McGowan \& D. Stephen, 1997. Vertically challenged limnology; contrasts between deep and shallow lakes. Hydrobiologia 342/343: 267-267.

Murphy, J. \& J. P. Riley, 1962. A modified single solution method for the determination of phosphate in natural waters. Analytika Chimica Acta 27: 31-36.

Ott, I., R. Laugaste \& T. Kõiv, 1999. Investigations of biodiversity in freshwater ecosystems in Estonia. In Hydrobiological Research in the Baltic Countries. Part I. Rivers and Lakes. Vilnius: 325368.

Padisák, J. \& C.S. Reynolds, 2003. Shallow lakes: The absolute, the relative, the functional and the pragmatic. Hydrobiologia 506509: 1-11.

Schindler, D., 1978. Factors regulating phytoplankton production and standing crop in the world's freshwaters. Limnol. Oceanogr. 23: 478-486.

Vighi, M. \& G. Chiaudani, 1985. A simple method to estimate lake P concentrations resulting from natural background loadings. Wat. Res. 19: 987-991. 